\title{
Mechanical and Wear Properties of 42CrMo Steel by Plasma Nitriding Assisted Hollow Cathode Ion Source
}

\author{
F.S. Zhao ${ }^{a, b}$, Z.H. Zhang ${ }^{c}$, M.H. Shao ${ }^{d}$, Y.J. Bi ${ }^{a, b}$, Y.Q. Zhao ${ }^{a}$, Z.W. Wang, ${ }^{a, b}$ Y. Li ${ }^{a, *}$ (D) H.H. Li ${ }^{a}$, \\ X.G. Xu ${ }^{a}$, Y.Y. He \\ a Yantai University, Department of nuclear equipment, Yantai 264005, PR China \\ ${ }^{b}$ Yantai University, Institute for Advanced Studies in Precision Materials, Yantai, 264005, China \\ ${ }^{c}$ Tsinghua University, State Key Laboratory of Tribology, Beijing 100084, PR China \\ ${ }^{d}$ Yantai University, School of Electromechanical Automobile Engineering, Yantai, 264005, China
}

Received: March 20, 2021; Revised: April 18, 2021; Accepted: May 11, 2021

\begin{abstract}
Plasma nitriding is a plasma-activated thermochemical method widely used to increase the fatigue strength, hardness and wear resistance of low-alloy steels. In this work, a new structure consisting of a hollow cathode metal plate can produce a hollow cathode discharge and heat the workpiece by radiation. This principle is used to perform hollow cathode source plasma nitriding (HCSPN). Herein, 42CrMo steels were treated by conventional plasma nitriding (CPN) and HCSPN treatments. The $42 \mathrm{CrMo}$ steels were nitrided at $525^{\circ} \mathrm{C}$ for $6 \mathrm{~h}$ in $\mathrm{NH}_{3}$ atmosphere. The mechanical and dry wear properties were measured by nano-indentation, Vickers micro-indentation and ball-on-disk tribometer, respectively. The $\mathrm{H}^{3} / \mathrm{E}^{* 2}$ ratio was $0.0274 \mathrm{GPa}\left(\mathrm{H}=11.51 \mathrm{GPa}\right.$ and $\left.\mathrm{E}^{*}=235.84 \mathrm{GPa}\right)$ for the $\mathrm{CPN}$ sample and $0.0276 \mathrm{GPa}$ $\left(\mathrm{H}=10.87 \mathrm{GPa}\right.$ and $\left.\mathrm{E}^{*}=215.54 \mathrm{GPa}\right)$ for the HCSPN sample. Compared with the untreated $42 \mathrm{CrMn}$ steel, all the nitrided samples possess increased fracture toughness. Because the workpiece was not used as a discharge cathode, this HCSPN treatment overcame the disadvantages of the conventional CPN treatment. Additionally, results showed that the surface of the HCSPN sample was smoother than that of the CPN sample, and its tribological performance was better.
\end{abstract}

Keywords: Plasma Nitriding, Hollow Cathodic Source, Hardness, Friction.

\section{Introduction}

$42 \mathrm{CrMo}$ steel is often used as the material of hydraulic piston. However, due to the high load and high impact working environment of the hydraulic system, the surface of the plunger is required to have high hardness, good wear resistance and fatigue strength ${ }^{1-3}$. Plasma nitriding is one of the most widely used surface modification methods to improve the surface hardness and wear resistance of various engineering materials ${ }^{4-7}$. In the Fe-N system ${ }^{8,9}$, nitriding low alloy steels may produce the following phases: $\gamma^{\prime}-\mathrm{Fe}_{4} \mathrm{~N}$ (fcc), $\varepsilon-\mathrm{Fe}_{2-3} \mathrm{~N}(h c p)$ and a nitrogen solid solution in an $\alpha-\mathrm{Fe}$ phase. Additionally, the alloying elements $(\mathrm{Cr}, \mathrm{V}$, and $\mathrm{Mo})$ usually dissolve in these nitrides. In most $\mathrm{CPN}$ applications the correct adjustment of the discharge parameters avoids the arc regime and the edge effects. However, some special workpieces need auxiliary heating system to reach the required processing temperature ${ }^{10}$.

Active screen plasma nitriding technology (ASPN) or cathodic cage plasma nitriding (CCPN) has been extensively studied by many researchers in the past decade ${ }^{11-16}$. As the cathode of the metal screen is bombarded by ions, iron particles are continuously sputtered and deposited on the workpiece, and nitrogen atoms diffuse into the inner part of the suspended workpiece to avoid the above problems during CPN treatment. Since the plasma is formed by the

*email: liyangytu@163.com glow discharge generated by the active screen, the workpiece should be closer to the active screen ${ }^{17-19}$.

This setup leads to the active screen that is used in most experiments being very small, and the distance between the active screen and workpiece is also required to be small, so it cannot be used in large-scale industrial production. When nitriding with an active screen with a large volume, the surface strengthening effect of the workpiece at the floating potential is not obvious. The hollow cathode discharge can be established in the holes and supply electrons, which has been used for etching and nitriding ${ }^{20-23}$. The plasma density, or electron concentration, increases to approximately $10^{12} /$ $\mathrm{cm}^{320}$. Alves et al. ${ }^{24}$ designed a cylindrical hollow cathode structure to nitride Ti implants and studied the wettability and roughness of the surface after nitriding. The results showed that there was no geometric change in the main implant after nitriding. Compared with the untreated implant, the surface texture was significantly improved, and the wettability was better. Fietzke and Zimmermann ${ }^{25}$ found that adding a strong axial magnetic field to the hot hollow cathode electron emitter, a multiplication of ion current density together with the ionization rate is improved. Gallo et al. ${ }^{26}$ designed a special hollow cathode. The cathode bar and anode bar were inserted into a cylinder, which could concentrate the plasma in the center of the cylinder, thereby obtaining a relatively uniform deposition layer. This structure required 
the chassis to fix the cathode and anode bar, and a specific distance between the bars was strictly required.

In this work, a new structure for a hollow cathode device is designed to be a plurality of metal plates arranged in a furnace during HCSPN treatment. Each metal plate has a plurality of long grooves arranged at intervals, and each groove is provided with holes arranged at intervals. The high ionization rate obtained via the hollow cathode effect resulted in an efficient heating workpiece. Under the same treatment conditions (temperature and time), the CPN and HCSPN experiments are carried out on the same device. This works aims to investigate the mechanical and dry wear properties of the $42 \mathrm{CrMo}$ steel by CPN and HCSPN processing.

\section{Materials and Methods}

The material used in this experiment was 42CrMo steel, and its chemical composition is shown in Table 1 . The samples were cut from hot roll plates with a size of $20 \times 20 \times 6 \mathrm{~mm}^{3}$. The surface hardness of $42 \mathrm{CrMo}$ steel is $320 \mathrm{HV}_{0.1}$. These samples were ground using several grades of SiC papers and then polished with a $3.0 \mu \mathrm{m}$ diamond suspension. Finally, the polished samples were cleaned by alcohol ultrasonication.

CPN and HCSPN treatments were conducted in an LDMC-20 pulsed plasma reactor ${ }^{27}$. The pulsed frequency of adopted pulse generator was $1000 \mathrm{~Hz}$ and pulse duty factor were $65 \sim 70 \%$. The $42 \mathrm{CrMo}$ steels were nitrided in $\mathrm{NH}_{3}$ gas using CPN and HCSPN treatments at the cathodic and floating potentials, respectively. Two treatments were conducted at $525^{\circ} \mathrm{C}$ for $6 \mathrm{~h}$ at a pressure of $400 \mathrm{~Pa}$. For the $\mathrm{CPN}$ processing, the $42 \mathrm{CrMo}$ steels samples were only heated by bombardment at the cathodic potentials. For the HCSPN processing, the hollow cathode was made up of AISI 1020 steel plates with $10 \mathrm{~mm}$ of thickness, and its chemical composition is shown in Table 1. There are uniformly distributed holes (8-mm diameter) in the plates and some of the grooves in the inner wall (Figure 1). The depth and breadth of the grooves were $5 \mathrm{~mm}$ and $8 \mathrm{~mm}$, respectively. The hollow cathode discharge was formed by these holes and grooves. There are four metal plates enclosed in a square, which can radiate and heat the workpiece. Hollow cathode discharge occurred when the size of the cathode fall area was the same as the separation distance. The loss of electrons was small because they were repelled by the negative wall of the cathode. The temperature of the substrates was monitored using a thermocouple, and control by computer system. The Voltage between electrodes was $800 \sim 850 \mathrm{~V}$ and current density was $5 \sim 6 \mathrm{~A} / \mathrm{cm}^{2}$.

X-ray diffraction (BRUKER D8 ADVANCE) was used to identify the structures of the untreated and nitrided samples. All samples were measured in the $2 \theta$ scan range of $30^{\circ}<2 \theta<90^{\circ}$ using a $\mathrm{Cu} \mathrm{K} \alpha(\lambda=1.5406 \AA)$ radiation source at a scan rate of $5 \mathrm{deg} / \mathrm{min}$, and the phases were identified using JCPDS database. Scanning electron microscopy (SEM) along with energy dispersive X-ray spectroscopy (EDS) were used to observe the microstructures and elemental distribution of the nitride layers, respectively. The composition of the nitrided samples was analyzed by X-ray photoelectron spectroscopy (XPS). XPS measurements were performed on an ESCALAB 250 electron spectrometer using an anodic $\mathrm{Al} \mathrm{K} \alpha \mathrm{X}$-ray source with excitation energies of $1486.6 \mathrm{eV}$. Calibration was achieved using the $\mathrm{C} 1 \mathrm{~s}$ peak of the surface contamination at $284.6 \mathrm{eV}$.

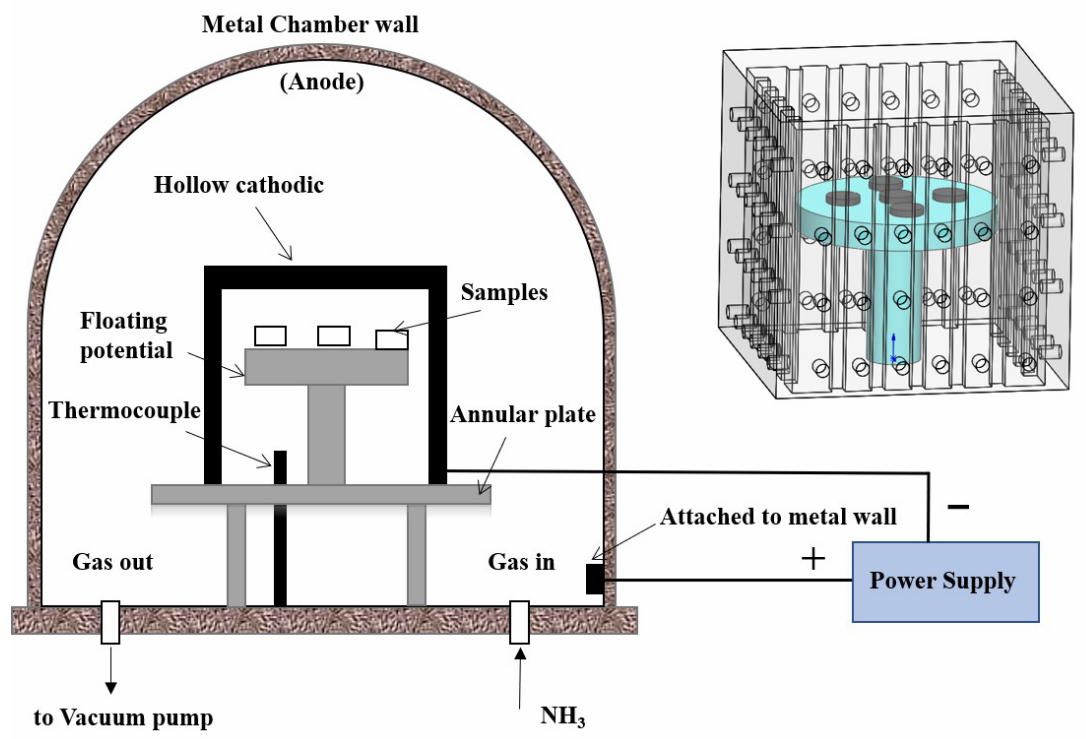

Figure 1. Schematic representation of the HCSPN apparatus.

Table 1. Chemical composition (wt \%) of 42CrMo steel and AISI1020 steel used in the present work.

\begin{tabular}{ccccccccc}
\hline & $\mathrm{C}$ & $\mathrm{Cr}$ & $\mathrm{Mo}$ & $\mathrm{Si}$ & $\mathrm{Mn}$ & $\mathrm{P}$ & $\mathrm{S}$ & $\mathrm{Fe}$ \\
\hline 42CrMo & $0.38 \sim 0.43$ & $0.80 \sim 1.20$ & $0.15 \sim 0.25$ & $0.15 \sim 0.35$ & $0.75 \sim 1.0$ & $<0.03$ & $<0.03$ & balance \\
\hline AISI 1020 & $0.17 \sim 0.23$ & $<0.25$ & - & $0.17 \sim 0.37$ & $0.40 \sim 0.65$ & $<0.03$ & $<0.03$ & balance \\
\hline
\end{tabular}


Nano hardness and Elastic modulus were measured by nano-indentation tester (NHT-2, CSM, Switzerland) with displacement resolution of $0.004 \mathrm{~nm}$. BerkovichB-T56 diamond indenter was used to apply $10 \mathrm{mN}$ load at the loading and unloading rate of $10 \mathrm{mN} / \mathrm{min}$ for $5 \mathrm{~s}$. Each sample was repeated for at least five times. Vickers hardness was measured by using a microhardness tester with a $100 \mathrm{gf}$ $(0.98 \mathrm{~N})$ load. A computer-controlled multifunctional tribometer(UMT-4, CETR, USA) was employed to carry out the reciprocating sliding wear tests. The corresponding friction pair was 52100 bearing steel balls $(\mathrm{SR}=4 \mathrm{~mm})$, and their hardness was $62 \mathrm{HRC}$. The frequency used in the experiment was $10 \mathrm{~Hz}$, and the load was $10 \mathrm{~N}$, forming a reciprocating $20 \mathrm{~mm}$ cycle. Each test was repeated at least 3 times in order to obtain reproducibility results. All the specimens were cleaned after the wear test in an ultrasonicator containing ethanol and observed by SEM. The volume of the wear tracks was

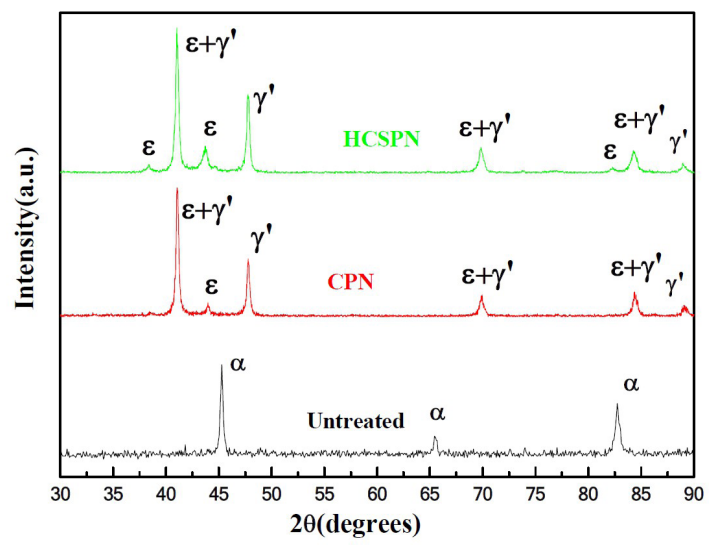

Figure 2. X-ray diffraction patterns of the different samples. measured a 3D white light interference surface topography (Zygo NexView; Zygo Corporation, Middlefield, CT, U.S.), which has a vertical resolution of $0.1 \mathrm{~nm}$. The $10 \mathrm{X}$ lens was used to obtained the surface wear topography. The wear rate $(\delta)$ calculation formula is expressed in Equation 1, as follows:

$$
\delta=\frac{V}{\sum W}
$$

Formula: $\mathrm{V}$ is the volume loss $\left(\mathrm{mm}^{3}\right)$ and $\sum \mathrm{W}$ is total work $(\mathrm{Nm})$.

\section{Results and Discussion}

Figure 2 shows the XRD patterns of the CPN and HCSPN nitrided samples. There are two identical phases in the nitrided layer, including $\varepsilon-\mathrm{Fe}_{2-3} \mathrm{~N}$ and $\gamma^{\prime}-\mathrm{Fe}_{4} \mathrm{~N}$. The strength of the $\varepsilon-\mathrm{Fe}_{2-3} \mathrm{~N}$ phase of HCSPN is higher than that of the CPN phase at $38.3^{\circ}$ and $44.2^{\circ}$. Figure 3 shows the surface micrographs of the CPN and HCSPN samples. There are some pits and wrinkles on the surface of the CPN sample. In addition, no edge effect is found on the surface of the HCSPN samples. When the hollow cathode electrode is heated, the $42 \mathrm{CrMo}$ steel samples quickly reach the desired temperature by heat conduction and radiation. Plasma forms on the screen instead of plasma forming on the sample. This device can not only heat the workpiece as a high-efficiency heat source but also generate plasma distributed in the discharge space and around the workpiece through diffusion and convection ${ }^{28}$. The $42 \mathrm{CrMo}$ steel can be effective treated in the floating potential for the HCSPN treatment. For the CPN samples, Figures $3 \mathrm{c}$ and $3 \mathrm{~d}$ show the cross-sectional micrographs of central and edge area to illustrate the measurements of the depth of the nitrided layers. It can be seen that the thickness
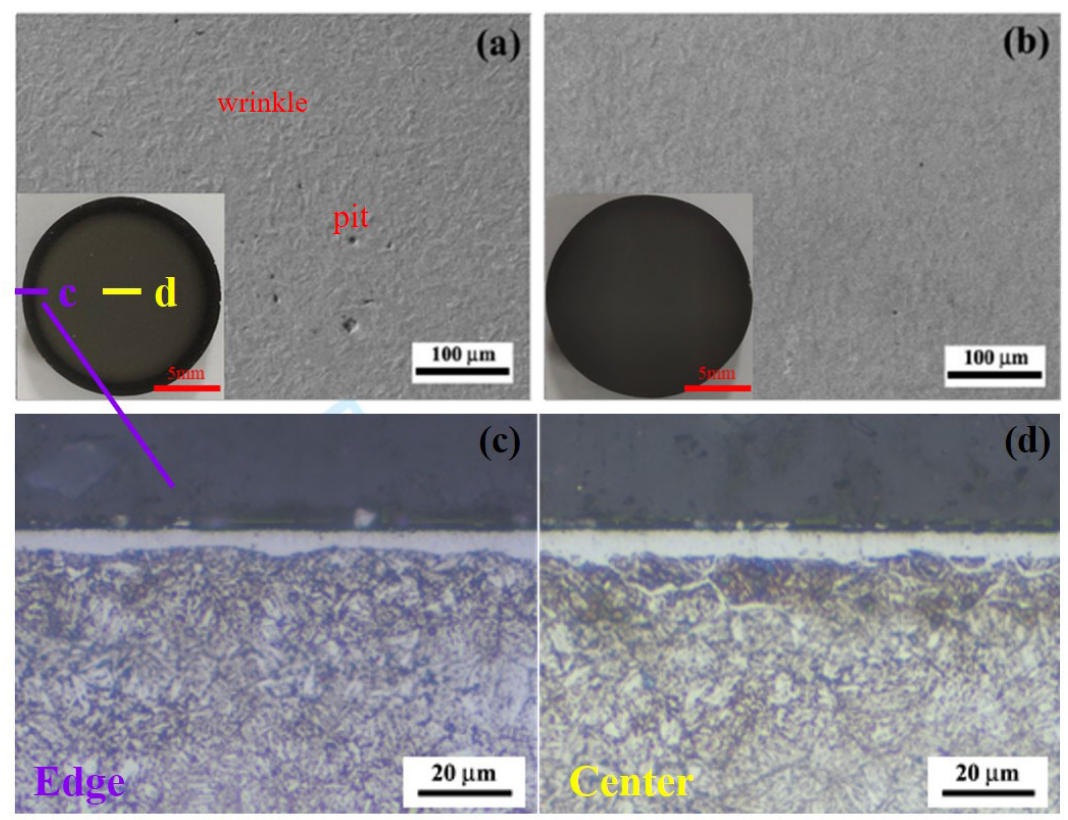

Figure 3. SEM surface topographies and optical photos of the (a)CPN and (b)HCPSN nitrided samples. Cross-sectional micrographs of edge (c) and central (d) area of the CPN nitrided sample. 
of edge area is slightly thinner that in the central area. Since the ionization phenomenon is stronger in the edge of the CPN sample due to the edge effect. This results show that the sputtering effect in the edge region is stronger and the compound layer is thinner.

Elemental mappings of the CPN (Figure 4) and HCSPN samples (Figure 5) were carried out by EDS. All nitrided samples show a distribution of nitrogen, oxygen, chromium, manganese and iron from the surface to the matrix. The nitrogen concentration in the compound layer is higher than that in the diffusion zone. Compared with HCSPN samples, a $\mathrm{Cr}$ and $\mathrm{O}$ rich layer was found on the outermost part of the CPN surface sample by analyzing the elemental mapping. Both CPN and HCPN samples presented a nitrided layer formed by $\varepsilon$ and $\gamma^{\prime}$ phases, it expects a similar composition for them. According to Figure 4 and Figure 5, a thicker $7 \mu \mathrm{m}$ nitrided layer was formed on the surface of the CPN sample, whereas a thinner nitride layer $(\sim 4 \mu \mathrm{m})$ was developed on HCPN sample surface.

The surface morphology and roughness of the CPN and HCSPN samples were observed by AFM in contact mode and are shown in Figure 6. The surface roughness (94.0 nm) of the CPN sample is higher than that of the HCPSN sample $(73.3 \mathrm{~nm})$. Our previously reported that the microscale surface roughness of the polished sample is about $6.1 \mathrm{~nm}^{27}$. The highest peak of the CPN sample is approximately $400 \mathrm{~nm}$, the lowest peak is approximately $-150 \mathrm{~nm}$, and the maximum peak difference is $550 \mathrm{~nm}$. However, the AFM images show that the HCSPN sample has a homogeneous surface morphology, and most vertical heights are less than $350 \mathrm{~nm}$, as shown in the profiles in Figure $6 \mathrm{~d}$. The dissolved nitrogen with higher concentrations strains the crystal lattice and form residual stresses. Very fine and dispersed precipitates are formed in the nitrogen rich region of the $\mathrm{CPN}$ modified layer, lead to increase the surface roughness. The surface of the HCSPN sample is smoother than that of the CPN sample. The reason for the change in the surface of the CPN sample is due to the ion bombardment and grain boundary bulging caused by lattice expansion after the solid solution is mixed with the matrix ${ }^{23}$.

Figure 7 shows the typical loading-unloading curves of the untreated, CPN and HCSPN samples, from which the quantities such as the hardness $(\mathrm{H})$ and effective Young's modulus $\left(\mathrm{E}^{*}\right)$ can be evaluated in Table 2. It should be noted that the hardness $(\mathrm{H}=7.31 \mathrm{GPa})$ and effective Young's modulus $\left(\mathrm{E}^{*}=250.68 \mathrm{GPa}\right)$ of the substrate are less than that of the nitrified samples. The $\mathrm{H}^{3} / \mathrm{E}^{* 2}$ ratio were $0.0274 \mathrm{GPa}$ $\left(\mathrm{H}=11.51 \mathrm{GPa}\right.$ and $\left.\mathrm{E}^{*}=235.84 \mathrm{GPa}\right)$ for the CPN sample and $0.0276 \mathrm{GPa}\left(\mathrm{H}=10.87 \mathrm{GPa}\right.$ and $\left.\mathrm{E}^{*}=215.54 \mathrm{GPa}\right)$ for the HCSPN sample. Compared with the untreated $42 \mathrm{CrMn}$
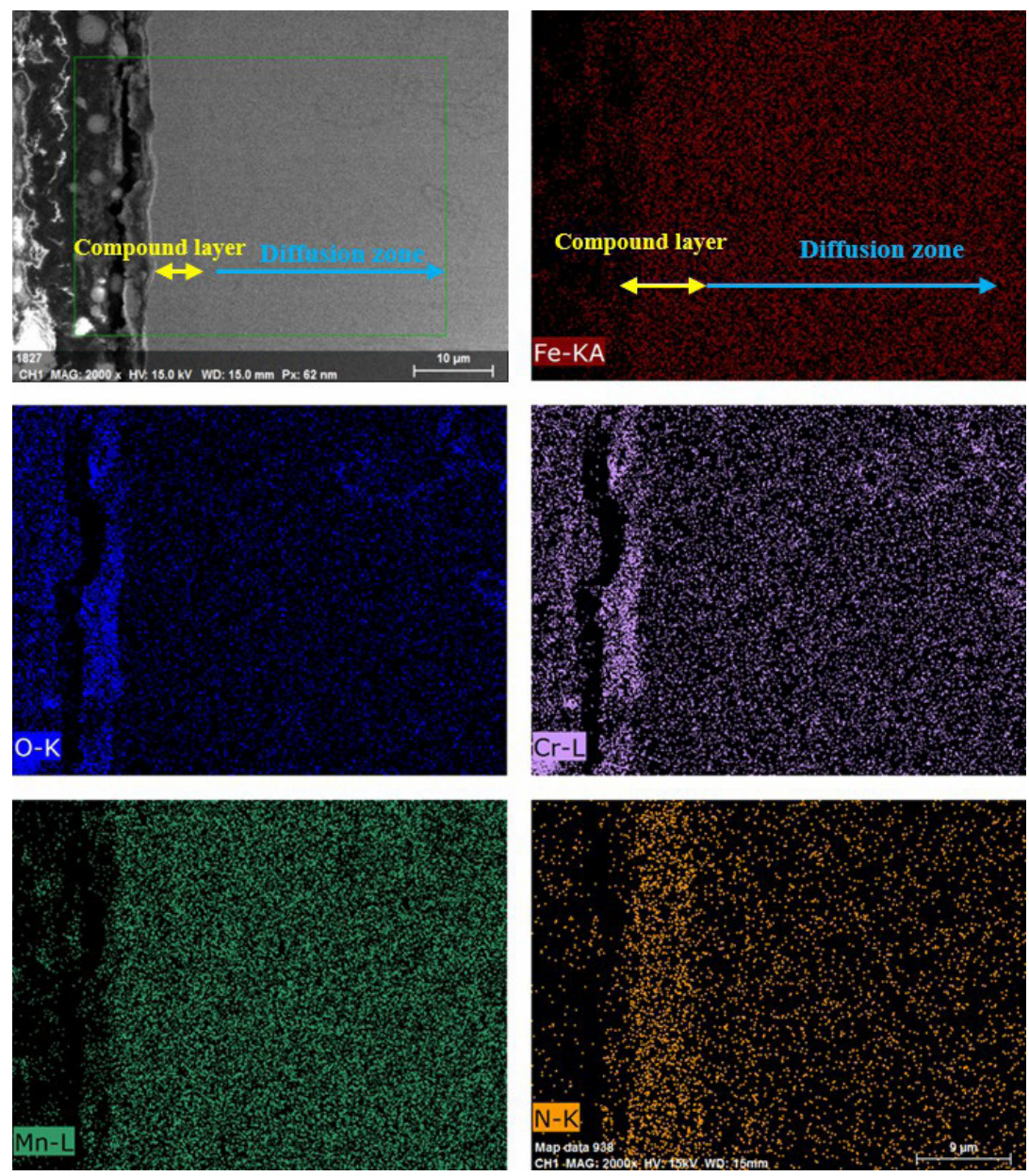

Figure 4. EDS elemental mapping scan along the cross-section of the nitrided layer of the CPN sample. 
Table 2. Surface nano-hardness and micro-hardness of the different samples.

\begin{tabular}{|c|c|c|c|c|c|c|c|}
\hline \multirow{2}{*}{ Samples } & Nano-hardness & $\begin{array}{l}\text { Elastic } \\
\text { modulus }\end{array}$ & $E^{*}$ & $\mathrm{H} / \mathrm{E}$ & $\mathrm{H} / \mathrm{E}^{*}$ & $\mathrm{H}^{3} / \mathrm{E}^{* 2}$ & $\begin{array}{c}\text { Micro- } \\
\text { hardness }\end{array}$ \\
\hline & /GPa & / GPa & & & & / GPa & $\mathrm{HV}_{0.1}$ \\
\hline Untreated & 7.31 & 228.12 & 250.68 & 0.0320 & 0.0291 & 0.0062 & 320 \\
\hline CPN & 11.51 & 214.61 & 235.84 & 0.0536 & 0.0488 & 0.0274 & 960 \\
\hline hespn & 10.87 & 196.14 & 215.54 & 0.0554 & 0.0504 & 0.0276 & 820 \\
\hline
\end{tabular}
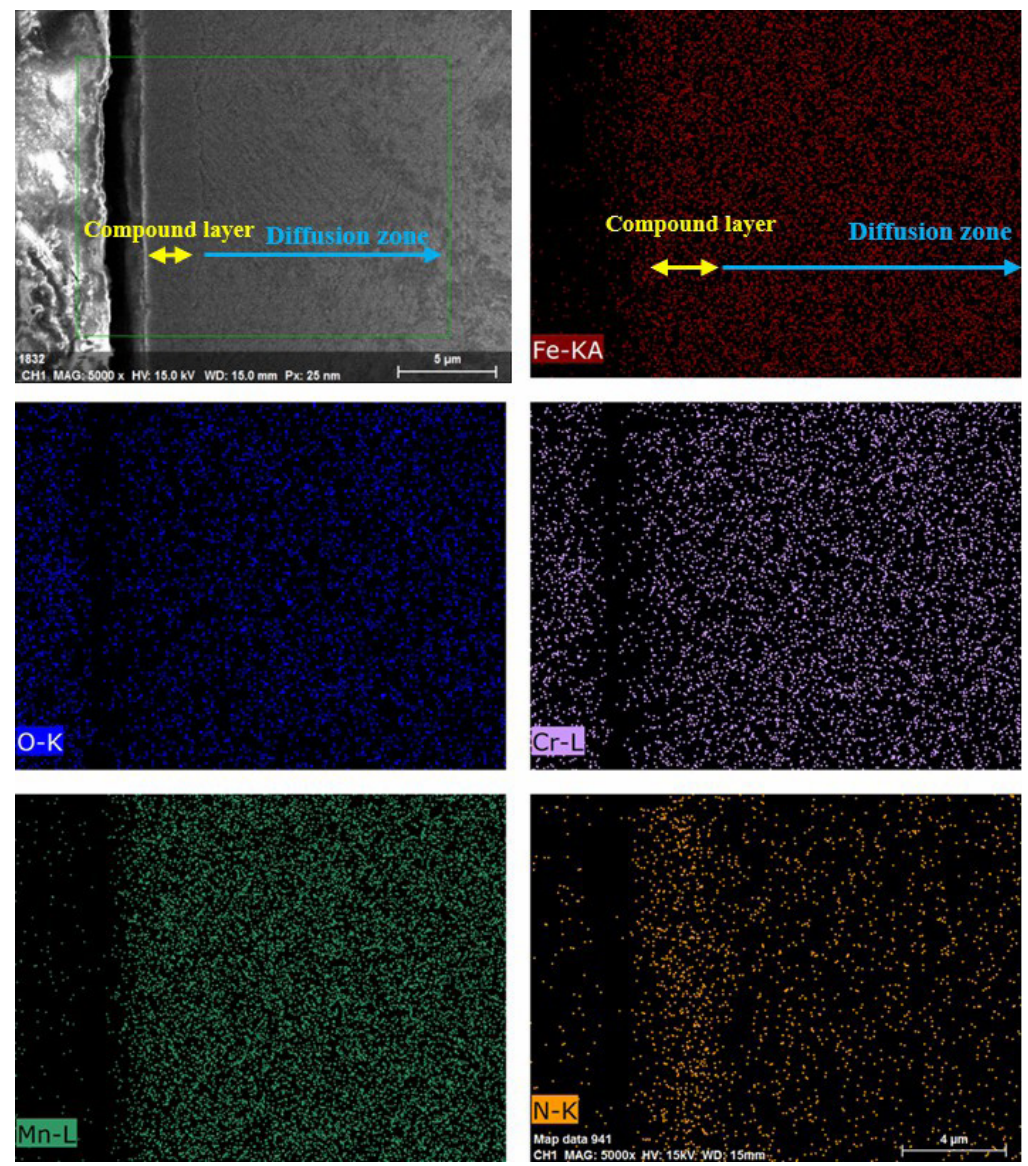

Figure 5. EDS elemental mapping scan along the cross-section of the nitrided layer of the HCSPN sample.

steel, all the nitrided samples possess increased fracture toughness. According to Leyland and Mathews ${ }^{29}$, the ratios of $\mathrm{H} / \mathrm{E}^{*}$ and $\mathrm{H}^{3} / \mathrm{E}^{* 2}$ is proportional to the indicators of the resistance against yielding and plastic deformation, respectively. thus, the larger the $\mathrm{H}^{3} / \mathrm{E}^{* 2}$ ratio is, the toughness of the nitride layer is better.

Figure 8 shows the hardness of $42 \mathrm{CrMo}$ steel after CPN and HCSPN treatment. The surface hardness of HCSPN is $820 \mathrm{HV}_{0.1}$, while that of CPN is $960 \mathrm{HV}_{0.1}$. It is generally considered that the sum of the matrix hardness value $\left(320 \mathrm{HV}_{0,1}\right)$ and $50 \mathrm{HV}_{0,1}$ is the thickness of hardened layer. The HCSPN sample reaches a hardness of $370 \mathrm{HV}_{0.1}$ at approximately $160 \mu \mathrm{m}$, while the samples treated with CPN reaches this matrix hardness at $230 \mu \mathrm{m}$. Under the cathode potential drop, nitrogen positive ions bombard the surface and diffuse to the deeper surface with higher energy for the $\mathrm{CPN}$ samples. The increase of $\mathrm{N}$ concentration can improve the $\mathrm{N}$ concentration gradient between the surface and the matrix, which must be in favor of the diffusion of $\mathrm{N}$ atoms to the $\alpha$-Fe matrix ${ }^{5,30}$. The hardness, the SEM and XRD results also show that the thickness and hardness of nitrided layer of the CPN were higher than those of the HCSPN.

Figure 9a shows the friction coefficients of the untreated, CPN, and HCSPN samples. The friction coefficient of the untreated samples changes little over time and remain between 0.7 and 0.8 . The friction coefficient of the HCSPN sample is maintained between 0.1 and 0.2 at the initial steps $(\sim 100 \mathrm{~s})$. The friction coefficient of the CPN sample is higher than that of the untreated sample after $25 \mathrm{~s}$. The friction coefficient of $\mathrm{CPN}$ is the highest at the final stage, which is mainly due to its high roughness. The results of the wear test show that the friction coefficient value decreases in the following order, $\mathrm{CPN}<$ untreated $<$ HCSPN.

Figure 10 shows the wear tracks of the untreated and nitrided samples. Table 3 shows the EDS results (at. \%) of the untreated and nitrided specimens of the marked area 
Table 3. EDS results (at. \%) of the untreated and nitrided specimens of the marked area (1-5) on the worn surface from the Figure 10.

\begin{tabular}{cccccccc}
\hline Point & $\mathrm{C}$ & $\mathrm{N}$ & $\mathrm{O}$ & $\mathrm{Si}$ & $\mathrm{Cr}$ & $\mathrm{Mn}$ & $\mathrm{Fe}$ \\
\hline $\mathbf{1}$ & 5.49 & - & 7.08 & 0.58 & 1.24 & 0.67 & 85.54 \\
\hline $\mathbf{2}$ & 2.50 & - & 59.03 & - & - & - & 38.47 \\
\hline $\mathbf{3}$ & 5.24 & 13.20 & 5.70 & - & 1.75 & - & 74.11 \\
\hline $\mathbf{4}$ & 0.46 & 14.81 & 3.40 & 0.79 & 1.07 & 1.03 & 78.44 \\
\hline $\mathbf{5}$ & 0.57 & - & 48.85 & 0.79 & 0.94 & 0.68 & 48.17 \\
\hline
\end{tabular}
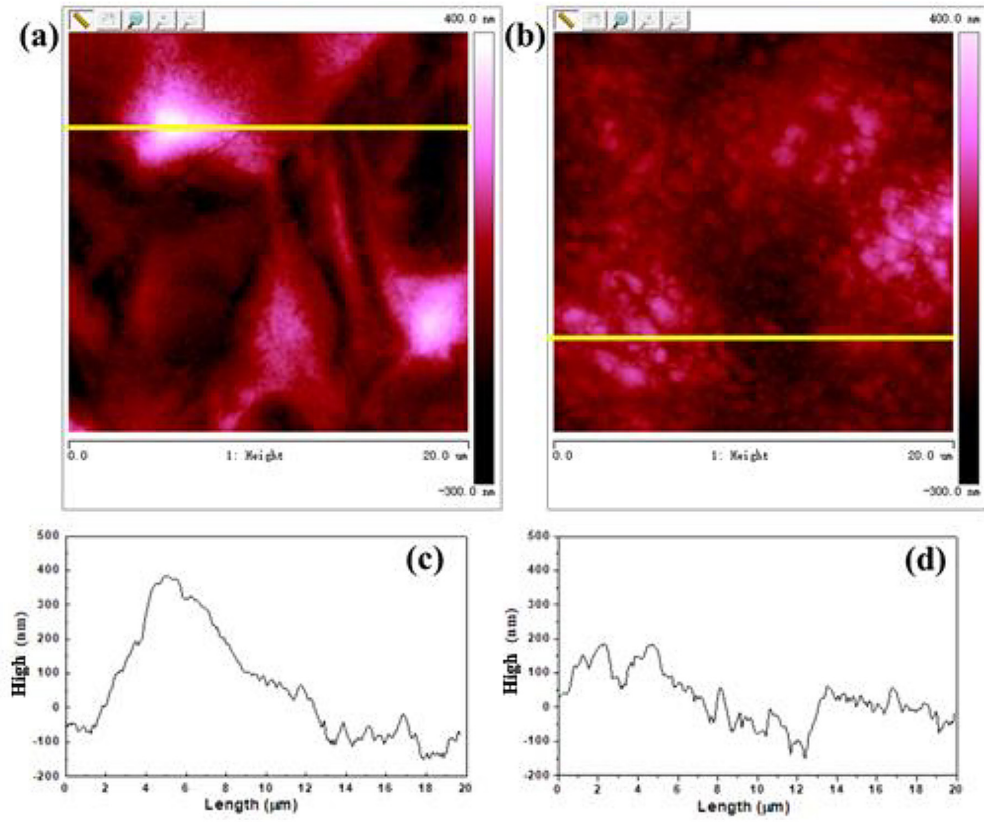

Figure 6. AFM images of the CPN (a) and HCSPN (b) samples.

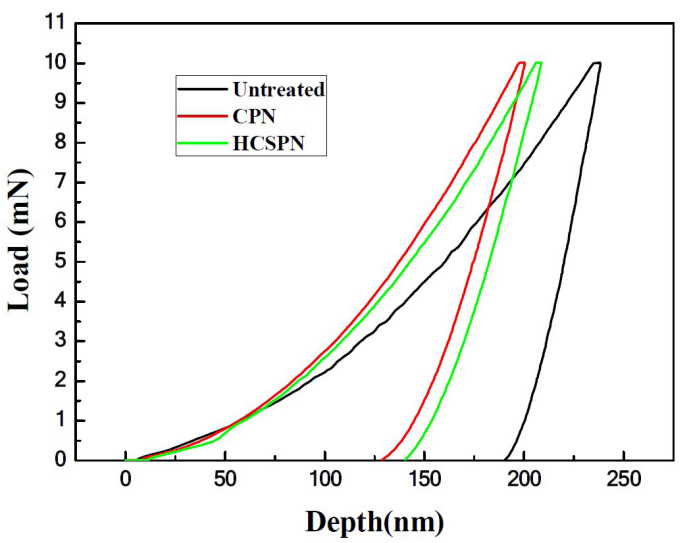

Figure 7. Typical loading-unloading curves of the different samples measured by nano-indentation tester.

(1-5) on the worn surface from the Figure 10. The largest wear track width $(\sim 520 \mu \mathrm{m})$ is observed on the surface of the untreated sample. It is found that serious plastic deformation and adhesion phenomena occur (Figure 10a), and the adhesive produced by friction continues to damage the surface, resulting in more scratch marks. It is considered that adhesive wear is what mainly occurs with untreated $42 \mathrm{CrMo}$ steel. Compared with the untreated sample, the wear

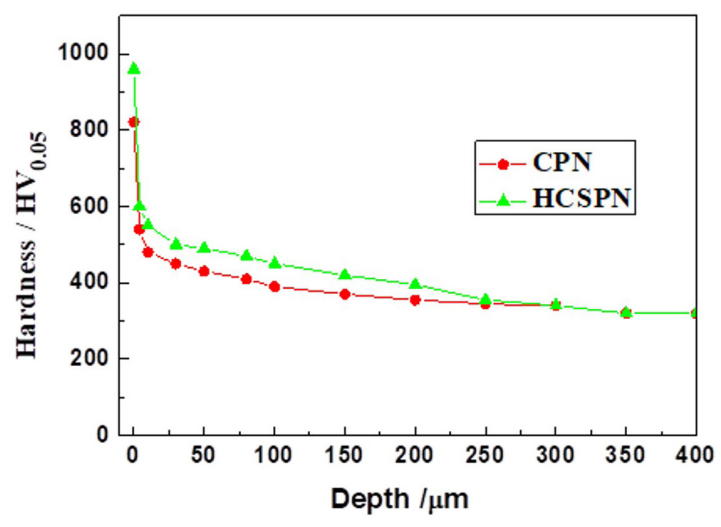

Figure 8. Microhardness distributions with depth for CPN and HCSPN samples.

track of the CPN sample is narrower $(\sim 420 \mu \mathrm{m})$ and only shallow traces are observed. Additionally, the EDS spectrum of area 2 in Figure 10e shows that the oxygen content on the wear surface is up to 59.03 at.\%. It can be considered that the main wear mechanism of the CPN sample is abrasive and oxidation wear. The HCSPN sample has the shallowest wear trace, with black flakes distributed in the wear trace $(\sim 480 \mu \mathrm{m})$. The EDS spectrum of area 4 in Figure 10f shows 


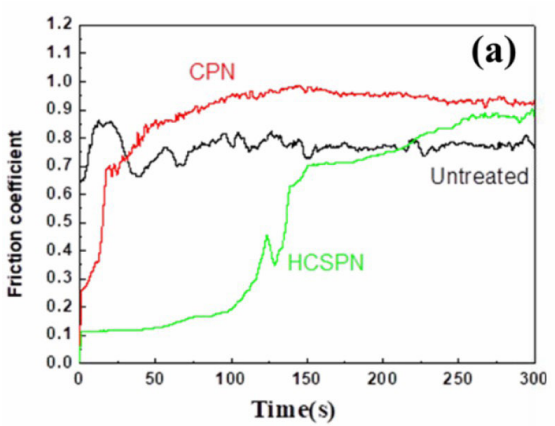

(a)Friction coeffificients

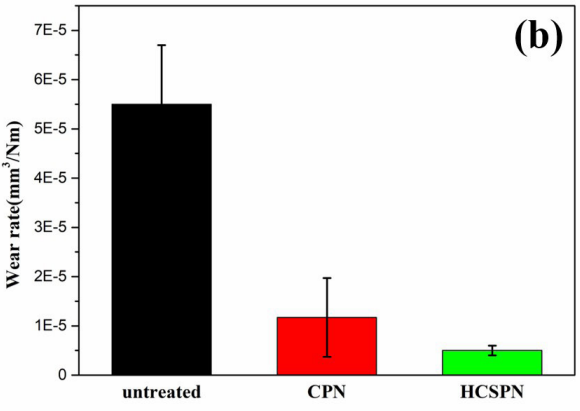

(b)Wear rates of the different samples

Figure 9. Friction coefficients (a) and wear rates (b) of the samples after the different treatments.
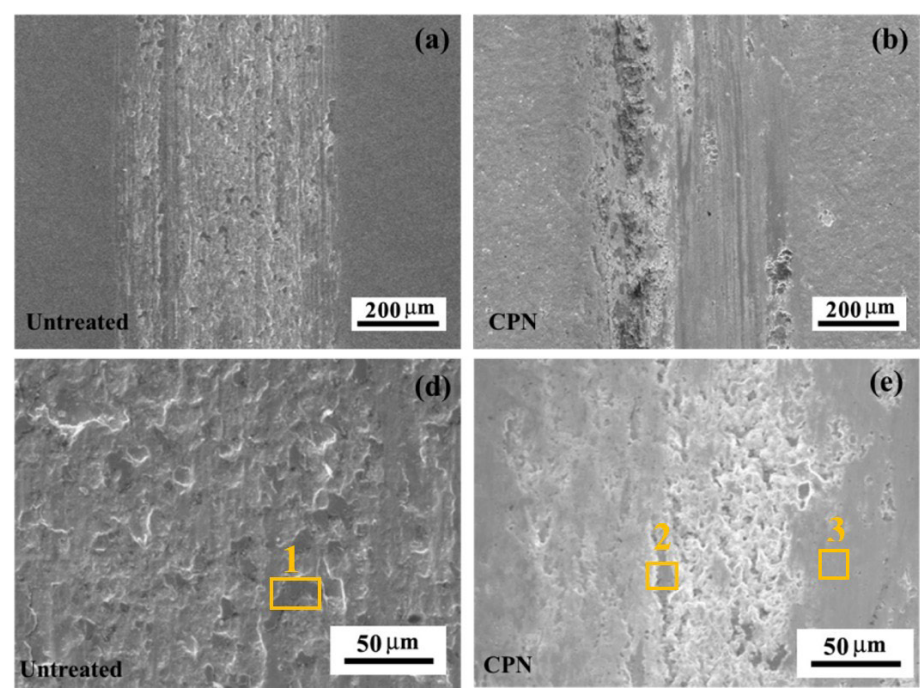

b)
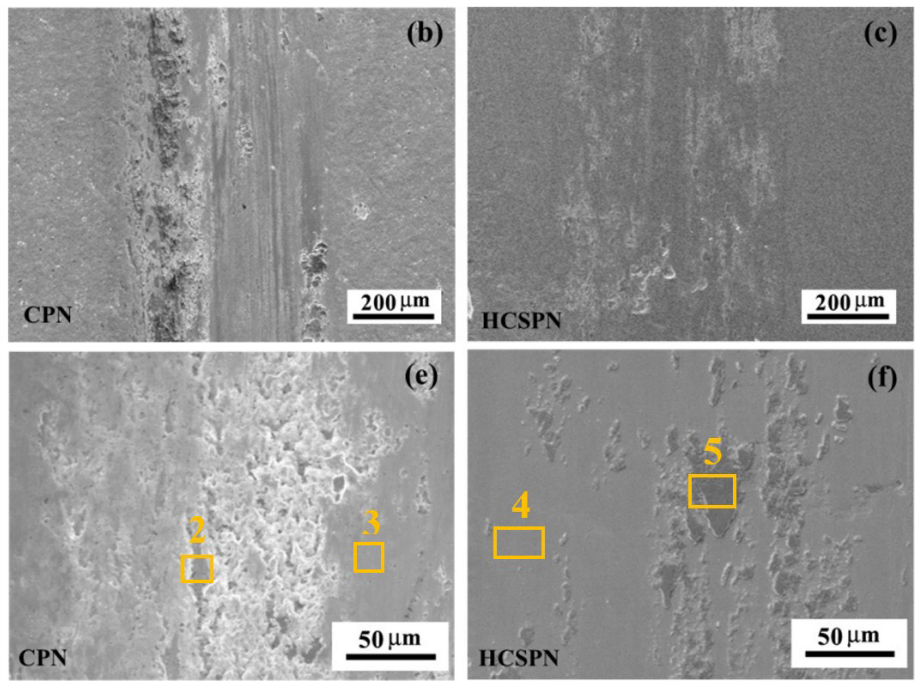

Figure 10. SEM images on the worn surface of the untreated (a and d), CPN (b and e), and HCSPN samples (c and f).

that the main elements on the surface of the HCSPN sample are $\mathrm{Fe}(78.44$ at.\%) and $\mathrm{N}$ (14.81 at.\%), which once again shows that the surface of the HCSPN sample produces a nitrided layer. The EDS spectrum of area 5 (Figure 10f) shows that $\mathrm{O}(48.85$ at.\%) replaces $\mathrm{N}$ as the main element, outside of $\mathrm{Fe}$ (48.17 at.\%), which indicates that the nitrided layer is oxidized after the wear test and results in oxidation wear. Figure $9 b$ further shows the wear rates of the different samples. It was found that the wear rate of the untreated samples is 5 times higher than that of the nitrided samples. Consequently, the wear rate of the CPN sample is slightly higher than that of the HCSPN sample. These characteristics enable these nitrided layers to effectively resist against hard AISI 52100 ball and an providing a superior wear resistance compared to untreated substrate. The $\mathrm{H}^{3} / \mathrm{E}^{* 2}$ parameter of these layer seems statistically similar $(\mathrm{CPN}=0.0274$ and $\mathrm{HCSPN}=0.0276$ ). The nitrided layers with the lower coefficients and the higher value of $\mathrm{H}^{3} / \mathrm{E}^{* 2}$ showed the smaller wear rate. The tribological properties of the CPN and HCSPN samples depend on the microstructure and toughness of the nitrided layer $\left(\mathrm{H} / \mathrm{E}\right.$ and $\left.\mathrm{H}^{3} / \mathrm{E}^{* 2}\right)$. The wear rate of $\mathrm{CPN}$ sample was higher than that of HCSPN one. Though the CPN presented a thicker nitrided compound layer and a deeper diffusion zone, it has a higher surface roughness.

Due to its relatively low hardness, the untreated $42 \mathrm{CrMo}$ steel surface is deformed during the wear test and exhibits high volume loss and high friction. The main wear mechanism of the untreated samples is adhesive wear. However, the main wear mechanism of the CPN sample is abrasive wear. The shallow furrow parallel to the sliding direction in the wear mark indicates that there is a slight amount of abrasive wear, and the width of the wear mark varies, mainly due to its high surface hardness.

Figure 11 shows the XPS fitting maps of the $\mathrm{O}_{1 \mathrm{~s}}, \mathrm{~N}_{1 \mathrm{~s}}$, and $\mathrm{Fe} 2 \mathrm{p}_{3 / 2}$ peaks of the nitrided surface and the wear scars of the HCSPN samples. For the nitrided surface, the existence of oxygen is due to the reaction of oxygen from the air in the nitriding process into the vacuum furnace ${ }^{31}$. The content of iron oxides at the wear scar is significantly higher than that at the initial nitrided surface, which can be proven from the binding energy peak height of the iron oxide binding energy at 529.5 and $530.25 \mathrm{eV}^{32}$. The existence of carbon-oxygen single bonds and carbon-oxygen double bonds may be due to the existence of certain pollution during the diffusion 

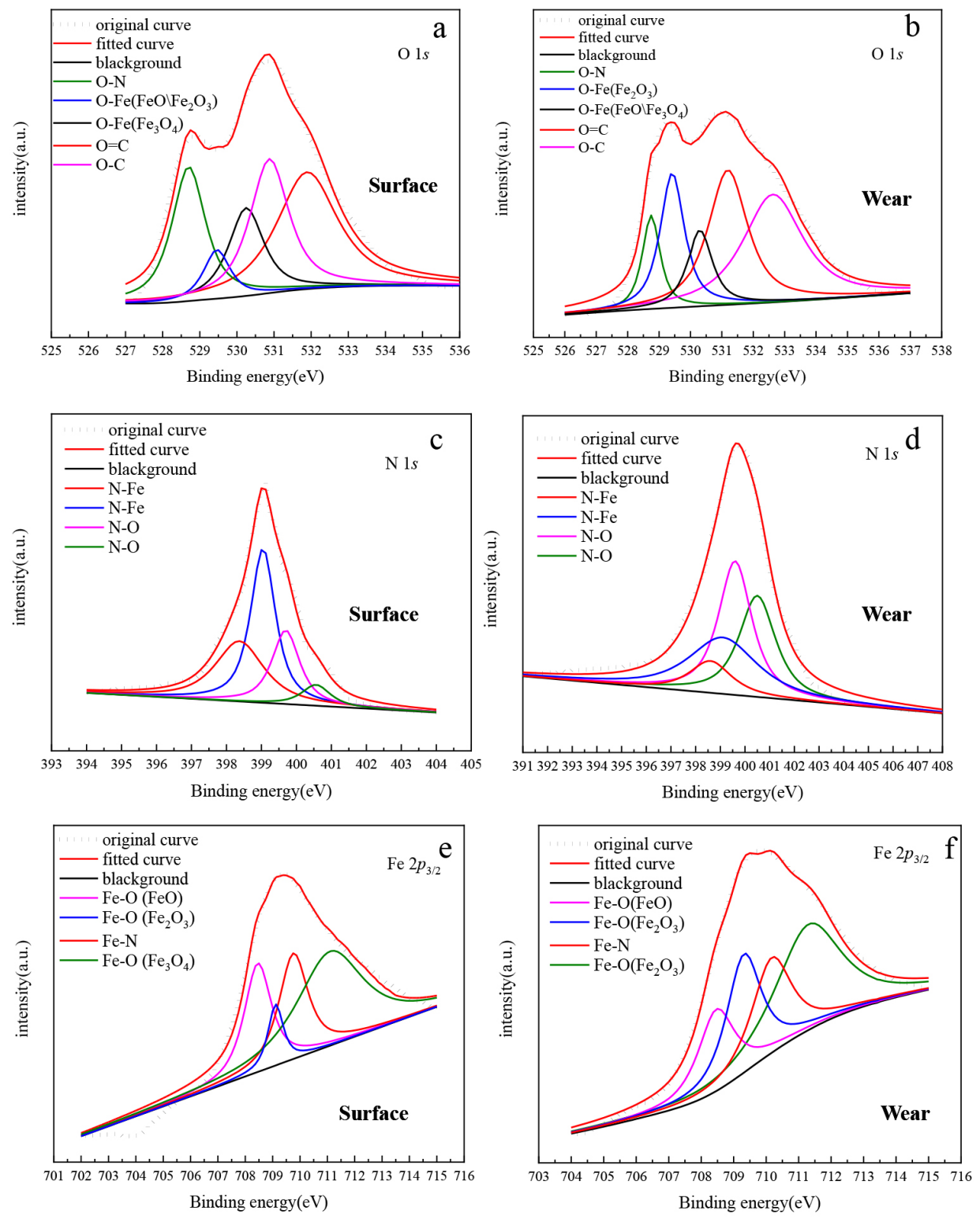

Figure 11. XPS deconvoluted profiles for (A) O 1s, (B) N 1s, (C) Fe 2p3/2 peaks on the nitrided surface and the wear scars of the HCSPN samples.

process. The $\mathrm{N}_{1 \mathrm{~s}}$ spectrum of the surface of the samples is composed of four peaks, including two strong peaks at $398.38 \mathrm{eV}$ and $399 \mathrm{eV}$, which correspond to iron nitride, and two weak peaks at $399.8 \mathrm{eV}$ and $400.5 \mathrm{eV}$, which correspond to nitrided oxides ${ }^{33}$. It is also found that the strong peak at the wear scars transfers from iron nitrides to oxynitrides. The decrease in the iron nitride peaks and the increase in the nitrogen oxide peaks prove this. According to the XPS spectrum of $\mathrm{Fe} 2 \mathrm{p}_{3 / 2}$, iron on the surface and in the wear scars of the CPN and HCSPN samples mainly exists in the form of iron oxide and iron nitride. The peak of $\mathrm{Fe}_{2} \mathrm{O}_{3}$ in the wear scars clearly increases, and the peak of $\mathrm{FeO}$ decreases. This result indicates that the iron is further oxidized, and the valence of iron increases during the friction process. The EDS analysis of the HCSPN sample also confirms this phenomenon. The results show that the main components of the wear debris are $\mathrm{Fe}_{2} \mathrm{O}_{3}$ and $\mathrm{Fe}_{3} \mathrm{O}_{4}$ under heavy loads. The XPS results (Figure 11f) show that the peak of $\mathrm{FeO}$ decreases gradually in the wear mark, while the peak of $\mathrm{Fe}_{2} \mathrm{O}_{3}$ clearly increases. This result indicates that the HCSPN samples have very slight oxidation wear.

Compared with the CPN samples, the friction coefficient of the HCSPN samples remains at a low level in the early stage until the nitrided surface is worn through after $200 \mathrm{~s}$, and the friction coefficient reaches a relatively stable level, which is closely related to the hardness and uniformity of the surface. 
The main reason for oxidation wear is the sharp increase in the contact temperature between the HCSPN surface and friction pair and the oxidation film formed by the reaction of oxygen in the atmosphere with the nitrided surface during friction. Alves et al. ${ }^{34}$ found that the microhardness magnitude of central area is much bigger in edges area due to thermal gradient in the CPN. On the contrary, the hardness values stayed uniform in the whole ASPN sample. When the floating sample is nitrided by the HCSPN treatment, the nitrided layer corresponds to a lower surface roughness and uniform hardness, which is beneficial for improving the tribological performance.

\section{Conclusions}

Herein, 42CrMo steels were successfully nitrided at $525^{\circ} \mathrm{C}$ for $6 \mathrm{~h}$ using CPN and HCSPN treatments at the cathodic and floating potentials, respectively. The new electrode structure can realize a stable and efficient hollow cathode discharge. Additionally, this structure can produce high-density and high-activity plasma while heating the workpiece by radiation. The $\varepsilon-\mathrm{Fe}_{2-3} \mathrm{~N}$ and $\gamma$ ' $-\mathrm{Fe}_{4} \mathrm{~N}$ phases are found in the nitrided layer of the CPN and HCSPN samples. However, the relative intensity of the $\varepsilon-\mathrm{Fe}_{2-3} \mathrm{~N}$ phase in the HCSPN sample is higher than that in the CPN sample. The surface hardness of HCSPN is $820 \mathrm{HV}_{0.1}$, and the thickness of the diffusion layer is $230 \mu \mathrm{m}$, while that of $\mathrm{CPN}$ is $960 \mathrm{HV}_{0.1}$ and $300 \mu \mathrm{m}$. The $\mathrm{H}^{3} / \mathrm{E}^{* 2}$ ratio are $0.0274 \mathrm{GPa}$ for the $\mathrm{CPN}$ sample and $0.0276 \mathrm{GPa}$ for the HCSPN sample, which is higher than that of the substrate $(0.0062 \mathrm{GPa})$. The untreated 42CrMo steel vs. the nitrided samples shows severe surface damage and high wear. The main wear mechanism of the CPN sample is abrasive and oxidation wear, while the main wear mechanism of the HCSPN sample is oxidation wear.

\section{Acknowledgments}

This work was supported by the Shandong Provincial Natural Science Foundation (Nos.ZR2018MEE016, ZR2018MEE005 and ZR2019MEM012), and the Innovation and Entrepreneurship Training Program for College Students of Yantai University (S202011066010).

\section{References}

1. Chen Y, Song L, Zhang C, Ye X, Song R, Wang Z, et al. Plasma nitriding without formation of compound layer for $38 \mathrm{CrMoAl}$ hydraulic plunger. Vacuum. 2017;143:98-101.

2. Wang W, He Y, Zhao J, Mao J, Hu Y, Luo J. Optimization of groove texture profile to improve hydrodynamic lubrication performance: theory and experiments. Friction. 2020;8(01):8394. http://dx.doi.org/10.1007/s40544-018-0247-1.

3. Cesconetto MCRL, Franco AR Jr, Vieira EA. Improving the abrasive wear resistance of a microalloyed steel by plasma nitriding. Mater Res. 2015;18(2):334-40. http://dx.doi. org/10.1590/1516-1439.307714.

4. Xu X, Yu Z, Hou C, Song W, Wang Y. Microstructure and properties of plasma-nitrided Fe-based superalloy Fe-25Ni-15Cr. Metall Mater Trans, A Phys Metall Mater Sci. 2017;48(7):1-13. http://dx.doi.org/10.1007/s11661-017-4114-x.

5. Dalibon EL, Heim D, Forsich C, Brühl SP. Mechanical behavior of nitrided $316 \mathrm{~L}$ austenitic stainless steel coated with a:C-H-Si. Procedia Mater Sci. 2015;9:163-70.

6. Li Y, Liu Z, Luo J, Zhang S, Qiu J, He Y. Microstructure, mechanical and adhesive properties of $\mathrm{CrN} / \mathrm{CrTiAlSiN} /$
WCrTiAlN multilayer coatings deposited on nitrided AISI 4140 steel. Mater Charact. 2019;147:353-64.

7. Reis R, Silva PGHMD, Villanova RL, Vianna AM, Bernardelli EA. Plasma Nitriding of ISO 5832-1 Stainless Steel with Intermittent Nitrogen Flow at $450^{\circ} \mathrm{C}$. Mater Res. 2020;23(1):41.

8. Hyodo K, Munetoh S, Tsuchiyama T, Takaki S. Empirical interatomic potential for Fe-N binary system based on FinnisSinclair potential. Comput Mater Sci. 2020;174:109500.

9. Kovács D, Quintana I, Dobránszky J. Effects of different variants of plasma nitriding on the properties of the nitrided layer. J Mater Eng Perform. 2019;28(9):5485-93.

10. Yao J, Yan F, Chen B, Yang Y, Xu Y, Yan M, et al. Dual-strengthening of steel surface and bulk via synergistic effect of plasma nitriding: a case study of M50 steel. Surf Coat Tech. 2021;409:126910.

11. Pintaude G, Rovani AC, das Neves JCK, Lagoeiro LE, Li X, Dong HS. Wear and corrosion resistances of active screen plasma-nitrided duplex stainless steels. J Mater Eng Perform. 2019;28(6):3673-82.

12. Naeem M, Shafiq M, Zaka-ul-Islam M, Díaz-Guillén JC, Lopez-Badillo CM, Ullah N, et al. Improved surface properties of AISI-304 by novel duplex cathodic cage plasma nitriding. Mater Lett. 2017;189:213-6.

13. Lin K, Li X, Dong H, Guo P, Gu D. Nitrogen mass transfer and surface layer formation during the active screen plasma nitriding of austenitic stainless steels. Vacuum. 2018;148:224-9.

14. Kovács D, Dobránszky J, Fodor T, Takáts V, Bonyár A. Investigation of the ASPN process of low alloy steel by using $\mathrm{Ni}$ or Cr coated active screens. Surf Coat Tech. 2020;394:125638.

15. Naeem M, Iqbal J, Zakaullah M, Shafiq M, Mujahid ZI, DíazGuillén JC, et al. Enhanced wear and corrosion resistance of AISI-304 steel by duplex cathodic cage plasma treatment. Surf Coat Tech. 2019;375:34-45.

16. Sousa RRMD, Moura YJL, Sousa PAO, Medeiros JQ No, Costa THC, Alves C Jr. Nitriding of AISI 1020 steel: comparison between conventional nitriding and nitriding with cathodic cage. Mater Res. 2014;17(3):708-13.

17. Ichimura S, Takashima S, Tsuru I, Ohkubo D, Matsuo H, Goto M. Application and evaluation of nitriding treatment using active screen plasma. Surf Coat Tech. 2019;374:210-21.

18. Domínguez-Meister S, Ibáñez I, Dianova A, Brizuela M, Braceras I. Nitriding of titanium by hollow cathode assisted active screen plasma and its electro-tribological properties. Surf Coat Tech. 2021;411:126998.

19. Costa PMO, Serra PLC, Monção RM, Menezes AS, Borges FMR, Costa THC, et al. Influence of Hastelloy's cathodic cage plasma deposition on corrosion resistance of AISI 304 stainless steel and of AISI D6 tool steel. Mater Res. 2021;24(1):341.

20. Muhl S, Perez A. The use of hollow cathodes in deposition processes: a critical review. Thin Solid Films. 2015;579:174-98.

21. Nikolov K, Bunk K, Jung A, Kaestner P, Bräuer G, Klages C-P. High-efficient surface modification of thin austenitic stainlesssteel sheets applying short-time plasma nitriding by means of strip hollow cathode method for plasma thermochemical treatment. Vacuum. 2014;110:106-13.

22. Yang L, Zhuo W, Liang W. Surface properties of nitrided layer on AISI $316 \mathrm{~L}$ austenitic stainless steel produced by high temperature plasma nitriding in short time. Appl Surf Sci. 2014;298:243-50.

23. Li Y, Zhang S, He Y, Zhang L, Wang L. Characteristics of the nitrided layer formed on AISI 304 austenitic stainless steel by high temperature nitriding assisted hollow cathode discharge. Mater Des. 2014;64:527-34.

24. Alves C Jr, Guerra CLB No, Morais GHS, Silva CF, Hajek V. Nitriding of titanium disks and industrial dental implants using hollow cathode discharge. Surf Coat Tech. 2006;200(11):3657-63.

25. Fietzke F, Zimmermann B. Plasma characterization and technological application of a hollow cathode plasma source with an axial magnetic field. Surf Coat Tech. 2010;205(5):1491-6. 
26. Gallo SC, Crespi ÂE, Cemin F, Figueroa CA, Baumvol IJR. Electrostatically confined plasma in segmented hollow cathode geometries for surface engineering. IEEE Trans Plasma Sci. 2011;39(11):3028-32.

27. Li Y, Bi Y, Zhang M, Zhang S, Gao X, Zhang Z, et al. Hollow cathodic plasma source nitriding of AISI 4140 steel. Surf Eng. 2021;37(3):351-9.

28. Olzon-Dionysio M, Campos M, Kapp M, Souza S, Souza SD. Influences of plasma nitriding edge effect on properties of 316 L stainless steel. Surf Coat Tech. 2010;204(21):3623-8.

29. Leyland A, Matthews A. On the significance of the $\mathrm{H} / \mathrm{E}$ ratio in wear control: a nanocomposite coating approach to optimised tribological behaviour. Wear. 2000;246(1-2):1-10.

30. Moszyński D, Kiełbasa K, Arabczyk W. Influence of crystallites' size on iron nitriding and reduction of iron nitrides in nanocrystalline Fe-N system. Mater Chem Phys. 2013;141(2):674-9.
31. Li Y, He YY, Xiu JJ, Wang W, Zhu YJ, Hu B. Wear and corrosion properties of AISI 420 martensitic stainless steel treated by active screen plasma nitriding. Surf Coat Tech. 2017;329:184-92.

32. Flori M, Gruzza B, Bideux L, Monier G, Robert-Goumet C, Cherré JP, et al. XPS, EPMA and microstructural analysis of a defective industrial plasma-nitrided steel. Surf Coat Tech. 2008;202(24):5887-94.

33. Li Y, Zhang SZ, Qiu JX, He Y-Y, Xiu J-J, Ye Q-W, et al. Effect of electric potentials on microstructure, corrosion and wear characteristic of the nitrided layer prepared on $2 \mathrm{Cr} 13$ stainless steel by plasma nitriding. Acta Metall Engl Lett. 2019;32(6):73345.

34. Alves C Jr, Araújo FO, Ribeiro KJB, Costa JAP, Sousa RRM, Sousa RS. Use of cathodic cage in plasma nitriding. Surf Coat Tech. 2006;201(6):2450-4. 